\title{
Improving the quality of health care in Canada
}

\author{
Irfan A. Dhalla MD MSc, Joshua Tepper MD MPH eMBA
}

Cite as: CMAJ 2018 October 1;190:E1162-7. doi: 10.1503/cmaj.171045

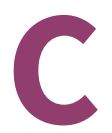

anadians are healthier than ever before, ${ }^{1}$ and in many respects, the quality of health care provided to Canadians is also better than ever. ${ }^{2-4}$ However, there are still large gaps between what we know to be high-quality health care and the care that many Canadians receive. Many jurisdictions, including Ontario, ${ }^{5}$ have adopted the definition of "quality" in health care put forward by the Institute of Medicine (now the Health and Medicine Division of the National Academies of Sciences, Engineering and Medicine). This definition holds that high-quality care is safe, timely, effective, efficient, equitable and patient centred. ${ }^{6}$ Improving quality is a complex endeavour. Health care quality is often examined through the lens of the clinician-patient encounter, yet the quality of care that individual health care professionals provide is also strongly determined by the broader contexts in which they train and work. The Institute of Medicine settled on its definition because it is comprehensive and highlights opportunities for improvement, without restriction to a particular sector, profession or type of organization. The supporting report also clearly acknowledges that the quality of care provided to patients is the responsibility of not just individual clinicians but also other actors in the health care system.

We use the well-recognized framework of the Institute of Medicine $^{6}$ to appraise the quality of health care in Canada, and also as a foundation for discussing strategies that can be used by system-level decision-makers who wish to improve health care.

\section{How good is the care that Canadians receive?}

In assessing the quality of health care provided to Canadians compared with that in other high-income countries, we rely primarily on two data sources: comparative data collated by the Organisation for Economic Co-operation and Development $(\mathrm{OECD})^{7}$ and annual surveys conducted by the Commonwealth Fund. ${ }^{8}$ Although international comparisons are often subject to various biases (e.g., people in one country may interpret a survey question differently from people in another, data may be collected differently in one country than another, and so on) and are limited in scope (e.g., it is usually impossible to compare patient-reported outcomes after specific surgeries or illnesses across different countries), the data can still be used to generate insights and provide opportunity for reflection.

Canadians know that we do not have a single health care system in Canada; rather, each of our 10 provinces and three

\section{KEY POINTS}

- Canadians are healthier than ever before, but there are still large gaps between what we know to be high-quality health care and the care that many Canadians receive.

- High-quality care is safe, timely, effective, efficient, equitable and patient centred.

- There is opportunity for improvement in all of these dimensions.

- Ways to improve the quality of care include expanding public funding for proven treatments, investing in primary care and embedding tools of improvement into practice.

- Improving care is more likely with the involvement of both front-line clinicians and patients.

territories holds primary responsibility for health care. Although there are many similarities between the 13 provincial and territorial systems, there are also important differences, not only in the way the systems are designed but also in the quality of care they provide.

In this article, we generally focus our attention at the national level; inevitably, this obscures important differences within Canada, between provinces and territories, and also between groups (e.g., Indigenous peoples and non-Indigenous Canadians). Also, although we focus here on health care, this does not diminish the importance of income, housing, education, social networks and other social determinants of health.

In Table 1, we use the six dimensions in the Institute of Medicine's framework to compare the quality of health care in Canada with that in other high-income countries.

\section{How can we improve the quality of health care in Canada?}

Health care quality can improve through changes in policy or behaviour at all levels (e.g., federal government, provincial and territorial governments, regional health authorities, health care delivery organizations, individual clinicians and patients). Here we focus primarily on a subset of evidence-based actions at the system level rather than on the actions that individual clinicians or patients can take. These actions would serve to improve care across all six of the dimensions described previously. 
Table 1: Comparison of quality of health care in Canada with that in other high-income countries, along all six dimensions in the Institute of Medicine framework

\section{Definitions, taken from Institute \\ Dimension of Medicine framework ${ }^{6}$}

\section{Quality of health care in Canada compared with that in other high-income countries}

Safe $\quad$ Avoiding injuries to patients from the care that is intended to help them.

Timely

Reducing waits and sometimes harmful delays for both those who receive and those who give care.

Effective Providing services based on scientific knowledge to all who could benefit, and refraining from providing services to those not likely to benefit (avoiding underuse and overuse, respectively).

Efficient Avoiding waste, including waste of equipment, supplies, ideas and energy.

Equitable Providing care that does not vary in quality because of personal characteristics such as gender, ethnicity, geographic location, and socioeconomic status.

Patientcentred
- Although there is ample evidence that Canadians suffer preventable harm owing to unsafe care, ${ }^{52,53}$ useful international comparisons focusing on the safety of health care are rare.

- According to OECD, Canadians undergoing hip or knee replacement are nearly twice as likely to develop a postoperative pulmonary embolism than individuals in a range of comparator countries, and Canadians undergoing abdominal surgery are $37 \%$ more likely to develop postoperative sepsis. ${ }^{54}$ However, it is not clear that these comparisons reflect genuine differences; OECD cautions in its report that "higher adverse event rates may signal more developed patient safety monitoring systems and a stronger patient safety culture rather than worse care." ${ }^{34}$

- Canadians wait longer for nonemergent care than people in many other high-income countries. ${ }^{55}$

- A recent Commonwealth Fund survey found that $25 \%$ of Canadians reported waiting longer than 8 weeks to see a specialist, compared with just 3\% in Switzerland and the United States, and between $10 \%$ and $20 \%$ in most other high-income countries. ${ }^{56}$

- With respect to primary care, another Commonwealth Fund survey found that only $53 \%$ of Canadian family physicians reported that their patients were able to receive an counterparts across a range of similarly high-income countries. ${ }^{56}$

- International comparisons suggest that Canadians have good health outcomes for many health conditions.

- For example, Canadians diagnosed with cancer can expect five-year survival rates that are as good as or better than those in most other countries. ${ }^{57}$ Similarly, on measures of "avoidable mortality" (i.e., mortality from conditions for which there is effective health care), Canada performs well in comparison with other countries. ${ }^{58}$

- Nevertheless, there are still many examples of both underuse and overuse in Canada that highlight opportunities for improvement. For example, less than $1 \%$ of public drug plan beneficiaries in Ontario receive first-line, evidence-based medications for alcohol use disorder in the year following this diagnosis. ${ }^{59}$ With respect to overuse, unnecessary testing is a classic example, with preoperative electrocardiography before low-risk surgery ranging from $3.4 \%$ to $88.8 \%$ across different hospitals in one study. ${ }^{60}$

- The amount of money Canada spends on health care, on a per capita basis, is similar to that in other high-income countries. ${ }^{61}$

- Looking beyond aggregate expenditure, Canada has fewer hospital beds and physicians ${ }^{62}$ for its population size than similar high-income countries, suggesting that physician and hospital care in Canada are reasonably efficient. ${ }^{7}$

- However, Canada may seem less efficient on other comparisons; for example, we pay more for prescription drugs ${ }^{63}$ than in most other high-income countries. and in hospitals without charge. Despite the removal of this financial barrier, many studies have shown that poorer Canadians are less likely than richer Canadians to receive evidencebased preventive health care. ${ }^{64}$ Poorer Canadians also have worse health outcomes than more wealthy Canadians. ${ }^{64}$ Similarly, Canadians who live outside large urban centres appear to receive lower-quality care and often have worse health outcomes.$^{65}$ This problem is particularly severe for Indigenous Canadians.

- In areas not covered by the Canada Health Act, such as home care and outpatient prescription drugs, financial barriers are common. For example, about 1 in 4 Canadians without prescription drug insurance do not take their medications as prescribed because of the cost, compared with about 1 in 15 Canadians who do have this insurance. ${ }^{66}$ problems getting care because of cost. This compares favourably to both the United States $(23 \%)$ and Australia (13\%), but unfavourably to Sweden (3\%), Norway (4\%) and the United Kingdom (4\%). ${ }^{67}$

- Commonwealth Fund surveys show that Canadians tend to report good experiences with their physicians compared with individuals living in other high-income countries. ${ }^{68}$

- However, there are areas in which patient-centredness could be improved in Canada. For example, many hospitals allow visitors only at certain times, ${ }^{69}$ and many patients report that they do not receive care in a culturally sensitive way. ${ }^{70}$ appointment on the day they asked for one, or the next day, compared with $72 \%$ of

- The Canada Health Act was designed to ensure that Canadians are treated by physicians

- The most recent Commonwealth Fund survey showed that $9 \%$ of older Canadians have 


\section{Expand public funding for treatments proven to be cost-effective}

The Canada Health Act has established a legal and regulatory foundation for the funding of "medically necessary" services provided by physicians or in hospitals. Some services, although proven to be effective and provide good value for money, are not publicly funded. One example is psychotherapy for patients with depression, which approximately doubles the response rate when added to medication. ${ }^{9}$ Accumulating evidence shows that when patients have to bear the cost of their own health care, they forgo important treatments. ${ }^{10}$ At the system level, decisions to increase public funding for treatments that are proven to be cost-effective would improve the quality of health care and likely the health of Canadians. ${ }^{11}$

Conversely, we should eliminate public funding for treatments that are ineffective, such as arthroscopic surgery for knee osteoarthritis. ${ }^{12}$ Federal and provincial decision-makers should also consider a recent recommendation to "put in place an ongoing mechanism to define standards for the modernization of the basket of publicly funded services in partnership with the provinces and territories." 13

\section{Invest in primary care}

Nearly 25 years ago, Starfield and colleagues showed that among high-income countries, the health care systems that were most oriented toward primary care tended to be those that had better outcomes, lower costs and greater patient satisfaction. They defined primary care as "first-contact, continuous, comprehensive and coordinated care provided to populations undifferentiated by gender, disease or organ system." 14

Although some Canadian provinces have, in recent years, begun to re-orient their primary care systems toward this vision, ${ }^{15}$ there is still a large gap between the primary care ideal and the quality of primary care received by most Canadians. Many efforts to reform primary care have focused on the methods used to pay family physicians, but payment reform alone is insufficient. ${ }^{16} \mathrm{We}$ agree with Hutchison and Glazier that a "clearly articulated policy road map that commands the support of the public and key stakeholders [i.e., physicians]" is needed. ${ }^{15}$ We also suggest that a system-level road map be designed to support evidence-based, practice-level "building blocks" such as engaged leadership, datadriven improvement, empanelment (assigning patients to individual primary care clinicians) and team-based care. ${ }^{17}$

\section{Use information systems that make it easier for clinicians to work together and with patients}

Most physicians and hospitals in Canada have now transitioned from using paper-based health records to electronic health records. ${ }^{18}$ However, in most provinces and territories, the systems that physicians use in their own offices do not communicate seamlessly with systems used by other health care providers (e.g., paramedics, hospital-based physicians, laboratories and home and community care providers). We need standards for interoperability to ensure these systems work together. This is not an innovative idea, ${ }^{19,20}$ but it is one that requires innovative leadership, from both the public and private sectors. We also need a legislative and regulatory framework that maximizes information sharing while also recognizing privacy rights.

Accumulating evidence clearly shows that the benefits of "open notes" (health records that can be easily viewed, and sometimes edited, by patients) exceed the harms, and that they may facilitate a new era of shared decision-making. ${ }^{21}$ For example, at the end of one large study involving more than 10000 patients, 99\% of patients stated they wanted to continue having access to their health records. ${ }^{22}$ Physicians were more likely than patients to note both disadvantages as well as advantages, but at the conclusion of the study, more than $85 \%$ of physicians reported that "making visit notes available to patients online is a good idea." ${ }^{22}$ When asked whether they wished to stop providing access to notes, not a single one of the more than 100 physicians in the study elected to stop.

\section{Engage patients}

Involving patients in decisions about their own health care is now expected within the context of the physician-patient relationship. However, involving patients at the system level in decisions about what services should be offered by a particular organization or the entire health care system, ${ }^{23}$ and how, is still the exception rather than the rule.

Involving patients, and the public, increases the legitimacy of decision-making ${ }^{24}$ and may improve the quality of the decisions made. Patients can be involved at the organizational level by actively participating in the design of strategic plans, operational plans or quality improvement plans. ${ }^{25}$ One large family practice in Ontario that engaged extensively with patients to improve their services found that doing so revealed improvement opportunities that had not occurred to clinicians and administrators. ${ }^{26}$ Also, encouragingly, they found this sort of engagement to be "inspiring and energizing" for patients and staff.

Patients can also be involved in improvement at the system level, either by inviting them to join decision-making committees that previously comprised only clinicians, researchers or administrators, ${ }^{27,28}$ or by developing "citizens' councils," composed entirely of noninsiders. ${ }^{29-31}$

\section{Standardize and embed quality improvement tools into practice}

Variation in practice is highly desirable when it is consistent with the evidence and reflects the values and preferences of patients. For example, the Canadian Task Force on Preventive Health Care has issued a weak recommendation in favour of screening mammography for women between the ages of 50 and $69 .{ }^{32}$ The weak recommendation implies that most women would want the recommended course of action, but some would not. In other words, it is a reasonable choice to forgo screening mammography. ${ }^{33}$

However, in many scenarios, variation appears to be related to differences in resource availability or in clinician preference or knowledge, rather than patient preferences. For example, some long-term care homes in Ontario are much more likely than others to transfer ill residents to emergency departments. ${ }^{34}$ The reasons for this are not completely understood, but it appears that factors unrelated to patient preference explain much of the variation. ${ }^{35}$ 
Developing and using guidelines and standards to help patients and clinicians make evidence-based decisions together, in a consistent way, will reduce variations in care and improve the quality of care we provide to Canadians. ${ }^{36}$ Using guidelines and standards will be easier for clinicians if system-level decision-makers also facilitate the development of tools, such as standardized order sets, that make it easy for patients and clinicians to pursue an evidence-based course of action. System-level decision-makers can also support initiatives that provide clinicians with data about the quality of care they provide. Doing so is proven to improve care; typically, the effects are modest, ${ }^{37}$ but sometimes they are dramatic. ${ }^{38}$

\section{Improve transparency for patients and the public}

Over the past few decades, there has been a revolution in transparency in many spheres of life, driven in part by improvements in computing power and ease of access to the Internet, and in part by changing societal norms. Although the evidence that transparency improves health outcomes remains limited, transparency is at minimum an important mechanism to ensure confidence. ${ }^{39}$

Transparency can also help identify "hot spots" for improvement. For example, the use of relatively simple statistical techniques ${ }^{40}$ can identify hospitals where mortality after a specific procedure is consistently higher than expected. ${ }^{41}$ It is important that these analyses be used primarily to offer support and guide improvement, and for punishment only when individuals have acted "wilfully, recklessly, or with a 'couldn't care less' attitude." 42

Where data can be used to make valid comparisons, decisionmakers at the system level should publicly report on the quality of care provided by individual organizations in a manner that can be readily understood by the public. Where the potential harms of public reporting outweigh the potential benefits, comparative data that can be used to focus quality improvement efforts should be provided confidentially to individual organizations and clinicians, as described above. ${ }^{38}$

Carefully conducted studies have shown that the harms of public reporting sometimes exceed the benefits, ${ }^{43}$ and predicting when this might happen is not always easy. However, as one observer has noted, we do not stop using effective medications just because some people have adverse effects. Instead, we continue to generate evidence so we can "make thoughtful clinical decisions about whether [a treatment is] worth it or not and in whom." 44 For some situations, we may need similar evidence to make thoughtful policy decisions about when it is appropriate to share data publicly.

\section{Involve physicians}

The quality improvement "agenda" should reinforce the natural desire of clinicians to provide the best care for their patients and not be seen as a burden or running counter to their daily efforts. Ensuring this is the case requires physician involvement. ${ }^{45}$ Many efforts to improve health care involve physicians too late in the development of the initiative, or superficially, or sometimes not at all. This is true with respect to other health care professionals as well, but physicians have a unique role in the Canadian health care system, given the legal, organizational and financial arrangements that influence physician practice. For example, in most Canadian hospitals, physicians are not employees and bill provincial health insurance plans directly for the services they provide. Decision-makers at the system level should pay more attention to the relationship between these arrangements and the likelihood that physicians will be involved in improvement efforts. ${ }^{46,47}$

\section{Ensure health education supports high-quality care}

Health education curricula in Canada at the undergraduate and postgraduate level receive substantial public funding and most health professions have nationally coordinated curriculum content. National and provincial education bodies and those that fund health education should support the delivery of high-quality care. This would include training all health care professionals to be capable in a set of core competencies in quality improvement. ${ }^{48}$ This competency development should extend throughout the professional career into continuing professional development programs.

The Royal College of Physicians and Surgeons of Canada, the College of Family Physicians of Canada and other organizations have recognized and responded to this need through the most recent revision of the CanMEDS framework, ${ }^{49}$ by creating a new "leader" role. One of the four key competencies for this new role is that physicians "contribute to the improvement of health care delivery in teams, organizations and systems." Health care professionals must learn not only how to provide care but also how to make systematic improvements to the care they provide.

\section{Ensure the well-being and positive experience of health professionals}

It is impossible to provide high-quality care in an environment where those at the front line of service delivery feel unwell, unsafe or have consistently negative experiences in their work environment.

For this reason, the Institute for Healthcare Improvement in the United States recently emphasized the concept of "joy in work," 50 and others have similarly articulated a need to expand the Triple Aim - which has included patient experience, population health and costs - to the Quadruple Aim, which would also include the experience of health care providers. ${ }^{51}$

\section{Conclusion}

The quality of health care in Canada is good, but arguably not great. Several key actions at the health-system level could go a long way to improving the quality of health care that Canadians receive. With thoughtful change, we could all benefit from a health care system that provides safe, timely, effective, efficient, equitable and patient-centred care at every opportunity. 


\section{References}

1. Deaths and age-standardized mortality rate, by province and territory. Ottawa: Statistics Canada; 2017. Available: www.statcan.gc.ca/tables-tableaux/sum-som/ 101/cst01/hlth86b-eng.htm (accessed 2017 June 11).

2. Ganesh A, Lindsay P, Fang J, et al. Integrated systems of stroke care and reduction in 30-day mortality: a retrospective analysis. Neurology 2016;86:898-904.

3. Stephenson AL, Sykes J, Stanojevic S, et al. Survival comparison of patients with cystic fibrosis in Canada and the United States: a population-based cohort study. Ann Intern Med 2017;166:537-46.

4. Wong MK, Morrison LJ, Qiu F, et al. Trends in short- and long-term survival among out-of-hospital cardiac arrest patients alive at hospital arrival. Circulation 2014;130:1883-90.

5. Quality matters: realizing excellent care for all. Toronto: Health Quality Ontario; 2017. Available: www.hqontario.ca/Portals/0/documents/health-quality/realizing -excellent-care-for-all-1704-en.pdf (accessed 2017 June 9).

6. Institute of Medicine. Crossing the quality chasm: a new health system for the 21st century. Washington (DC): The National Academies Press; 2001. Available: https:// nap.edu/catalog/10027/crossing-the-quality-chasm-a-new-health-system-for-the (accessed 2017 June 9).

7. Ontario health statistics 2017. Paris (FR): Organisation for Economic Co-operation and Development; 2017. Available: www.oecd.org/els/health-systems/health -data.htm (accessed 2017 July 2).

8. The complete series. New York: The Commonwealth Fund; 2018. Available: www. commonwealthfund.org/series/international-health-policy-surveys (accessed 2018 May 24).

9. Pampallona S, Bollini P, Tibaldi G, et al. Combined pharmacotherapy and psychological treatment for depression: a systematic review. Arch Gen Psychiatry 2004; 61:714-9.

10. Mann BS, Barnieh L, Tang K, et al. Association between drug insurance cost sharing strategies and outcomes in patients with chronic diseases: a systematic review. PLoS One 2014;9:e89168.

11. Stanbrook MB. Canada can afford universal pharmacare - no more excuses. CMAJ 2015;187:475.

12. Siemieniuk RA, Agoritsas T, Brignardello-Petersen R, et al. Arthroscopic surgery for degenerative knee arthritis and meniscal tears: a clinical practice guideline. BMJ 2017;357:j1982.

13. Recommendations. In: Fit for purpose: findings and recommendations of the external review of the Pan-Canadian Health Organizations - summary report. Ottawa (ON): Health Canada; 2018. Available: www.canada.ca/en/health -canada/services/health-care-system/reports-publications/health-care-system/ findings-recommendations-external-review-pan-canadian-health-organization. html\#a6 (accessed 2018 May 24).

14. Starfield B. Is primary care essential? Lancet 1994;344:1129-33.

15. Hutchison B, Glazier R. Ontario's primary care reforms have transformed the local care landscape, but a plan is needed for ongoing improvement. Health Aff (Millwood) 2013;32:695-703.

16. Bazemore A, Phillips RL Jr, Glazier R, et al. Commentary. Advancing primary care through alternative payment models: lessons from the United States and Canada. J Am Board Fam Med 2018;31:322-7.

17. Bodenheimer T, Ghorob A, Willard-Grace R, et al. The 10 building blocks of high-performing primary care. Ann Fam Med 2014;12:166-71.

18. A conversation about digital health: annual report 2015-2016. Toronto: Canada Health Infoway; 2016. Available: www.infoway-inforoute.ca/en/component/ edocman/3098-annual-report-2015-2016/view-document?temid=101 (accessed 2017 June 11).

19. Halamka JD, Tripathi M. The HITECH era in restrospect. N Engl J Med 2017;377: 907-9.

20. Washington V, DeSalvo K, Mostashari F, et al. The HITECH era and the path forward. NEngl J Med 2017;377:904-6.

21. Bell SK, Delbanco T, Walker J. OpenNotes: how the power of knowing can change health care. NEJM Catalyst 2017 Oct. 14. Available: http://catalyst. nejm.org/opennotes-knowing-change-health-care/ (accessed 2017 June 18).

22. Delbanco T, Walker J, Bell SK, et al. Inviting patients to read their doctors' notes: a quasi-experimental study and a look ahead. Ann Intern Med 2012;157:461-70.

23. Carman KL, Dardess P, Maurer M, et al. Patient and family engagement: a framework for understanding the elements and developing interventions and policies. Health Aff (Millwood) 2013;32:223-31.

24. Friedman A. Beyond accountability for reasonableness. Bioethics 2008;22:101-12.

25. Engaging with patients and caregivers about quality improvement: a guide for health care providers. Toronto: Health Quality Ontario; 2016. Available: www. hqontario.ca/portals/0/documents/qi/qip/patient-engagement-guide-1611-en.pdf (accessed 2017 June 11).

26. Kiran T, Davie S, MacLeod P. Citizen engagement in primary care. Ann Fam Med 2018;16:175.
27. Ontario Health Technology Advisory Committee. Toronto: Health Quality Ontario; 2018. Available: www.hqontario.ca/Evidence-to-Improve-Care/ Health-Technology-Assessment/Ontario-Health-Technology-Advisory-Committee (accessed 2018 June 1).

28. How drugs are considered: funding decisions. Toronto: Ministry of Health and LongTerm Care; 2013. Available: www.health.gov.on.ca/en/pro/programs/drugs/how drugs_approv/funding_ced.aspx (accessed 2018 June 1).

29. Canada needs "defined model" of universal pharmacare, citizen panel urges: "Necessary Medicines" report presented today to Commons health committee. cbcnews 2016 Dec. 6. Available: www.cbc.ca/news/health/pharmacare-citizen -panel-1.3882481 (accessed 2017 Aug. 11).

30. Citizens' council. Toronto: Ministry of Health and Long-Term Care; 2012. Available: www.health.gov.on.ca/en/public/programs/drugs/councils/ (accessed 2018 June 1).

31. Citizens council. London (UK): National Institute for Health and Care Excellence; 2018. Available: www.nice.org.uk/get-involved/citizens-council (accessed 2018 June 1).

32. Breast cancer. Ottawa: Canadian Task Force on Preventive Health Care; 2011. Available: https://canadiantaskforce.ca/guidelines/published-guidelines/breast-cancer/ (accessed 2018 June 1).

33. Heath I. It is not wrong to say no. BMJ 2009;338:b2529.

34. Gruneir A, Bronskill SE, Newman A, et al. Variation in emergency department transfer rates from nursing homes in Ontario, Canada. Healthc Policy 2016;12:76-88.

35. Baker LC, Bundorf MK, Kessler DP. Patients' preferences explain a small but significant share of regional variation in Medicare spending. Health Aff (Millwood) 2014;33:957-63.

36. Goitein L, James B. Standardized best practices and individual craft-based medicine: a conversation about quality. JAMA Intern Med 2016;176:835-8.

37. Ivers N, Jamtvedt G, Flottorp S, et al. Audit and feedback: effects on professional practice and healthcare outcomes. Cochrane Database Syst Rev 2012;(6):CD000259.

38. Guru V, Fremes SE, Naylor CD, et al. Public versus private institutional performance reporting: what is mandatory for quality improvement? Am Heart J 2006;152:573-8.

39. Lee V. Transparency and trust-online patient reviews of physicians. N Engl J Med 2017;376:197-9.

40. Spiegelhalter DJ. Funnel plots for comparing institutional performance. Stat Med 2005;24:1185-202.

41. Martin GP, Dixon-Woods M. After Mid Staffordshire: from acknowledgement, through learning, to improvement. BMJ Qual Saf 2014;23:706-8.

42. Williams L. National Advisory Group on the Safety of Patients in England. A promise to learn - a commitment to act. Improving the safety of patients in England. London (UK): Crown copyright; 2013. Available: https://assets.publishing.service.gov.uk/ government/uploads/system/uploads/attachment_data/file/226703/Berwick_ Report.pdf (accessed 2018 May 24).

43. Joynt KE, Blumenthal DM, Orav J. Association of public reporting for percutaneous coronary intervention with utilization and outcomes among Medicare beneficiaries with acute myocardial infarction. JAMA 2012;308:1460-8.

44. Jha A. Weighing the risks and benefits: what health policy can learn from clinical medicine. In: An ounce of evidence/Health policy [blog]. 2012 Oct. 9. Available: https://blogs.sph.harvard.edu/ashish-jha/2012/10/09/weighing-the-risks-and -benefits-what-health-policy-can-learn-from-clinical-medicine/(accessed 2018 May 24).

45. Aerde JV, Dickson G. Accepting our responsibility: a blueprint for physician leadership in transforming Canada's health care system. Ottawa: Canadian Society of Physician Leaders; 2017. Available: www.physicianleaders.ca/assets/whitepapercspl0210.pdf (accessed 2017 Aug. 11).

46. Dhalla IA, Detsky AS. Aligning incentives for academic physicians to improve health care quality. JAMA 2011;305:932-3.

47. Guidance for developing an effective hospital-physician relationship. Toronto: Ontario Hospital Association, Ontario Medical Association; 2015. Available: www.oha.com/Professional\%20lssues1/OHA-OMA\%20Guidance\%20for\%20 Developing\%20an\%20Effective\%20Hospital-Physician\%20Relationship\%20 -\%20Full\%20Version\%20\%282015\%29.pdf (accessed 2018 May 15).

48. Wong BM, Holmboe ES. Transforming the academic faculty perspective in graduate medical education to better align educational and clinical outcomes. Acad Med 2016;91:473-9.

49. CanMEDS. Ottawa: Royal College of Physicians and Surgeons of Canada; 2018. Available: www.royalcollege.ca/rcsite/canmeds-e (accessed 2018 May 24).

50. Perlo J, Balik B, Swensen S, et al. IHI framework for improving joy in work. IHI white paper. Cambridge (MA): Institute for Healthcare Improvement; 2017.

51. Bodenheimer T, Sinsky C. From triple to quadruple aim: care of the patient requires care of the provider. Ann Fam Med 2014;12:573-6.

52. Baker GR, Norton PG, Flintoft V, et al. The Canadian Adverse Events Study: the incidence of adverse events among hospital patients in Canada. CMAJ 2004; 170:1678-86.

53. Wong BM, Dyal S, Etchells EE, et al. Application of a trigger tool in near real time to inform quality improvement activities: a prospective study in a general medicine ward. BMJ Qual Saf 2015;24:272-81. 
54. Surgical complications. In: Health at a glance. Paris (FR): Organisation for Economic Co-operation and Development; 2018. Available: www.oecd-ilibrary.org/sites/ health_glance-2017-en/1/2/6/9/index.html?itemld=/content/publication/health_ glance-2017-en\&_csp_=980fcbc145e1f57ab4011c6cda9e970d\#sect-64 (accessed 2018 June 1).

55. Experiencing integrated care: Ontarians' views of health care coordination and communication. Toronto: Health Quality Ontario; 2015. Available: www.hqontario.ca/ Portals/0/documents/pr/report-experiencing-integrated-care-1504-en.pdf (accessed 2017 June 9).

56. How Canada compares: results from the Commonwealth Fund 2015 International Health Policy Survey of Primary Care Physicians. Ottawa: Canadian Institute for Health Information, Canadian Institutes of Health Research; 2016. Available: www.cihi.ca/sites/default/files/document/2015-cmwf-chartpackenrev-web.pptx (accessed 2017 June 9).

57. Allemani C, Weir HK, Carreira H, et al. Global surveillance of cancer survival 19952009: analysis of individual data for 25676887 patients from 279 population-based registries in 67 countries (CONCORD-2). Lancet 2014;385:997-1010.

58. Health indicators 2012. Ottawa: Canadian Institute for Health Information and Statistics Canada; 2012. Available: https://secure.cihi.ca/free_products/health_ indicators_2012_en.pdf (accessed 2017 June 9).

59. Spithoff S, Turner S, Gomes T, et al. First-line medications for alcohol use disorders among public drug plan beneficiaries in Ontario. Can Fam Physician 2017; 63:e277-83.

60. Kirkham KR, Wijeysundera DN, Pendrith C, et al. Preoperative testing before low-risk surgical procedures. CMAJ 2015;187:E349-58.

61. Health spending. Paris (FR): Organisation for Economic Co-operation and Development; 2015. Available: https://data.oecd.org/healthres/health-spending.htm (accessed 2017 June 9).
62. Doctors. Paris (FR): Organisation for Economic Co-operation and Development; 2015. Available: https://data.oecd.org/healthres/doctors.htm (accessed 2017 June 9).

63. Pharmaceutical spending. Paris (FR): Organisation for Economic Co-operation and Development; 2017. Available: https://data.oecd.org/healthres/pharmaceutical -spending.htm (accessed 2017 June 9).

64. Income and health: opportunities to achieve health equity in Ontario. Toronto: Health Quality Ontario; 2016. Available: www.hqontario.ca/Portals/0/documents/system -performance/health-equity-report-en.pdf (accessed 2017 June 9).

65. Health equity in Northern Ontario. Toronto: Health Quality Ontario; 2017 (accessed 2017 Jun 9]. Available: www.hqontario.ca/System-Performance/ Specialized-Reports/Health-Equity-in-Northern-Ontario (accessed 2017 June 9).

66. Law MR, Cheng L, Dhalla IA, et al. The effect of cost on adherence to prescription medications in Canada [abstract]. CMAJ 2012;184:297-302.

67. Osborn R, Doty MM, Moulds D, et al. Older Americans were sicker and faced more financial barriers to health care than counterparts in other countries. New York: The Commonwealth Fund; 2017. Available: www.commonwealthfund.org/ publications/journal-article/2017/nov/older-americans-were-sicker-and-faced -more-financial-barriers (accessed 2018 June 1).

68. Commonwealth Fund Survey 2016. Ottawa: Canadian Institute for Health Information; 2016. Available: www.cihi.ca/en/commonwealth-fund-survey-2016 (accessed 2017 June 9).

69. Much more than just a visit: a review of visiting policies in select Canadian acute care hospitals. Ottawa: Canadian Foundation for Healthcare Improvement; 2015. Available: www.cfhi-fcass.ca/sf-docs/default-source/patient-engagement/better -together-baseline-report.pdf?sfvrsn=10 Nov (accessed 2017 Mar. 13).

70. Pathy R, Mills KE, Gazeley S, et al. Health is a spiritual thing: perspectives of health care professionals and female Somali and Bangladeshi women on the health impacts of fasting during Ramadan. Ethn Health 2011;16:43-56.
Competing interests: Irfan Dhalla and Joshua Tepper both report that they are salaried employees of Health Quality Ontario.

This article was solicited and has been peer reviewed.

Affiliations: Health Quality Ontario (Dhalla, Tepper); Department of Medicine (Dhalla) and Department of Family and Community Medicine (Tepper) and Institute of Health Policy,
Management and Evaluation (Dhalla, Tepper), University of Toronto; St. Michael's Hospital (Dhalla, Tepper), Toronto, Ont.

Contributors: Both authors contributed to the conception and design of the work, drafted the manuscript, revised it critically for important intellectual content, gave final approval of the version to be published and agreed to be accountable for all aspects of the work.
Acknowledgements: The authors are grateful to Richard Alvarez, Adalsteinn Brown, Dennis Kendel, Tara Kiran, Andreas Laupacis, Angela Morin, Pat Rich and Brian Wong for providing thoughtful feedback on earlier versions of this article, and to Susan Harrison for both thoughtful feedback and editorial assistance.

Correspondence to: Irfan Dhalla, Irfan.Dhalla@hqontario.ca 